\title{
Overnutrition and Associated Factors Among High School Adolescents in Mid COVID-19 Pandemic in Ethiopia: Neglected Public Health Concern
}

\author{
Michael Belay', Abdu Oumer (D)', Neil Abdureshid ${ }^{2}$, Ahmed Ale $^{3}$ \\ 'Department of public health, College of Medicine and Health Sciences, Dire Dawa University, Dire Dawa, Ethiopia; ${ }^{2}$ Department of Midwifery and \\ College Quality Improvement Coordinator, College of Medicine and Health Sciences, Dire Dawa University, Dire Dawa, Ethiopia; ${ }^{3}$ School of Medicine, \\ College of Medicine and Health Sciences, Dire Dawa University, Dire Dawa, Ethiopia \\ Correspondence: Abdu Oumer, Tel +251966365785, Email omab2320@gmail.com
}

\begin{abstract}
Background: Adolescent overnutrition is becoming a global public health problem, increasing at an alarming rate in developing countries. Overnutrition increases the risks of serious diet-related chronic diseases, including type 2 diabetes, hypertension, cardiovascular disease, and stroke. However, there is limited evidence on the magnitude and risk factors of overnutrition in the study area.

Objective: To determine the magnitude of overnutrition and associated factors among school adolescents in Dire Dawa, Eastern Ethiopia.

Methods: A cross-sectional study was conducted from May to June 2021 among 498 adolescent students selected using a multi-stage sampling procedure. A systematic random sampling technique was employed. Self-administered questionnaires, including food frequency and anthropometric measurement, were used to collect the data. The BMI-for-age $Z$ score was calculated using the WHO Anthro-Plus. A binary logistic regression model was fitted with an odds ratio, and $95 \%$ confidence levels. Statistical significance is declared at a p-value below 0.05 .

Results: A total of 498 (98.4\%) were included with the overall prevalence of overnutrition of 26.1\% (95\% CI: 22.3-29.9), where $23.7 \%$ and $2.4 \%$ had overweight and obesity, respectively. Being female (AOR $=3.32 ; 95 \%$ CI: $1.65-6.63$ ), attending at private school $(\mathrm{AOR}=4.97 ; 95 \% \mathrm{CI}: 1.72-14.35)$, having sweet food preferences $(\mathrm{AOR}=6.26 ; 95 \%$ CI: 3.14-12.5), snacking $(\mathrm{AOR}=3.05 ; 95 \% \mathrm{CI}: 1.11-8.36)$, sedentary behavior $(\mathrm{AOR}=3.20 ; 95 \% \mathrm{CI}: 1.67-6.09)$, and eating while watching $\mathrm{TV}$ $(\mathrm{AOR}=2.95 ; 95 \% \mathrm{CI}: 1.47-5.95)$ were significantly associated with overnutrition.

Conclusion: Overnutrition is a major emerging public health problem in eastern Ethiopia. School type, sex, sweet food preferences, habits of snacking, sedentary behaviors, and eating while watching TV were significantly associated with overnutrition. Therefore, public health strategies to curb overweight and obesity among high school adolescents are urgently needed in order to reduce the prevalence and its adverse complications.
\end{abstract}

Keywords: high school, adolescents, body mass index, overweight, obesity, associated factors

\section{Background}

Adolescence is a transition period (10-19 years) from childhood to adult life, ${ }^{1}$ reaching about $25.1 \%$ of the world population where the majority resides (88\%) in developing countries. ${ }^{2}$ Adolescence is a period characterized by a change in many physiological behaviors that greatly influences diet choices and lifestyles. ${ }^{3}$ Due to the effects of urbanization, globalization, and prevailing food insecurity, there is a rising trend in the occurrence of malnutrition among adolescents. Due to such challenges, malnutrition (including underweight and overnutrition) is becoming a challenging public health issue globally. 4

Overweight and obesity (here referred to as overnutrition) is defined as excess body weight characterized by a body mass index (BMI) for-age $z$ score above one. ${ }^{5}$ Globally, over the last decades, it has become clear that being overweight 
and obese (overnutrition) kill more people than being underweight. ${ }^{5,6}$ Adolescent overnutrition is one of the most serious public health challenges of the 21 st century. Overweight affects 207 million (17.3\%) of adolescents worldwide, with a growing burden and negative consequences in low- and middle-income countries. ${ }^{6,7}$ Another estimate also showed that 80 million adolescents are obese, and 41 million among 15 to 19 year-old adolescents are obese, with a sustained increase (12\% increase from 2010 to 2016 ), and projected to double by $2030 .^{2}$

Adolescents in low- and middle-income countries, are becoming victims of alarming underweight, micronutrient deficiencies, and overnutrition in general, creating a triple burden of malnutrition. ${ }^{4}$ Overnutrition is becoming a lifethreatening health issue as a result of the complex influences of globalization, with overnutrition-related noncommunicable disease morbidity and mortality increasing. ${ }^{8}$ Prevailing malnutrition during pregnancy and infant and young child feeding with an alarming stunting rate cumulatively predisposes adolescents to overnutrition. ${ }^{8}$ Growth retardation during pregnancy and childhood malnutrition are thought to increase the risk of adult obesity and chronic noncommunicable diseases. ${ }^{9-11}$ Beyond the short-term health consequences, the problem persists into adulthood and older age, where the impacts are severe. ${ }^{10,12}$ In addition, the problem is prevailing in developing countries, where the rate of increase and adverse consequences are more rampant than in developed countries. ${ }^{13}$

In Ethiopia, there is no national level data, but studies from Addis Ababa, Gondar, Hawasa, and Bahir Dar towns revealed that the prevalence of overweight/obesity in adolescents was $18.2 \%, 5.9 \%, 15.6 \%$, and $12.5 \%$, respectively. ${ }^{14-17}$ Despite improvements in deaths related to malnutrition and communicable diseases, non-communicable diseases (diabetes, hypertension, cardiovascular diseases, and others) are becoming the leading causes of mortality (70\%) and contribute to a larger share of the disease burden. ${ }^{18}$ This huge burden is deeply rooted in the prevailing overweight and obesity, which can be prevented in early childhood, and adolescence. ${ }^{19}$ A study showed that $8.9 \%$ and $2.3 \%$ of children and adolescents were overweight and obese, respectively. ${ }^{20}$ This huge burden, and even more in urbanized settings, warrants having disaggregated evidence on the potential common and context-specific risk factors for overnutrition, which could critically guide potential obesity prevention and control strategies in the specific context and the nation at large. ${ }^{21}$

The study area, Dire Dawa, is an urbanized area with a diverse ethnic population, a border with Djoubouti, and hot weather conditions, so we hypothesized that adolescent overnutrition would be a major concern. It is imperative to have concrete evidence on the burden and important avoidable risk factors that predispose adolescents to overnutrition, which is critical for targeted public health interventions. It is of great importance to have concrete evidence on the burden and potential risk factors that predispose to overnutrition. This will give a policy and program directions to address overnutrition and its consequences among adolescents. Thus, this paper explored the magnitude and identified the risk factors associated with adolescent overnutrition in the eastern parts of Ethiopia.

\section{Materials and methods}

\section{Study setting and design}

This school-based survey was conducted in one of the two administrative cities, Dire Dawa, located in the eastern part of Ethiopia. It is $515 \mathrm{~km}$ away from Addis Ababa. In Dire Dawa, there are a total of 26; 11 governmental and 15 private schools. The study was conducted from May to June 2021. The target population of this study was all adolescent high school students aged 10-19 years in the study area. Among these, a random sample of 504 adolescents from both governmental and private high schools was included in the sample. Adolescents with body deformities such as scoliosis, kyphosis, severe abdominal swelling, and those seriously ill and unable to communicate were excluded, as this makes anthropometric measures unreliable where height measurement might be inaccurate.

\section{Sample Size determination and sampling procedure}

The minimum sample required for the first objective was calculated using sample size estimation for a single proportion estimate. We assumed the prevalence of overnutrition among adolescents (18.2\%), ${ }^{17,22}$ a 5\% significance level, at a $95 \%$ confidence level and precision of $5 \%$. The sample size has become 229. On the other hand, a sample size for a second objective was also estimated using a sample size for a cross-sectional study comparing the risk of overnutrition due to 
different factors. We took a power of $80 \%$ and a $95 \%$ confidence interval. However, the samples estimated taking sex $(\mathrm{n}=144)$, physical activity $(\mathrm{n}=141)$ and type of school $(\mathrm{n}=155)$, which is far below the required sample for the first objective. Thus, we took the larger sample size for the first objective and design effect of 2 and a $10 \%$ non response rate to account for multistage sampling and non volunteers during data collection. Thus, a total of 504 samples were required to conduct the study and achieve the objectives.

A multi-stage stratified sampling technique was used to select study subjects. First, the total sample was proportionally allocated to private and governmental high schools. Based on their ownership, the high schools ( 26 high schools) in Dire Dawa town were stratified into government $(n=4)$ and private schools $(n=6)$. From each selected high school, a sample frame was prepared for all sections of grades 9 and 10 separately where the allocated sample size was selected using lottery methods.

\section{Variables of the study}

The outcome variable was over-nutrition (which is a composite indicator of overweight and obesity). On the other hand, socio-demographic and family-level characteristics (school type, sex, age, grade level, religion, family size, father's education level, mother's education level, father's occupation, mother's occupation, and wealth index scores), dietary habits (fruit, cereals, vegetables, milk and milk products, meat, frequency of regular meal intake, snack and sweet food), physical activity (total physical activity cumulated using work, transport, and leisure time related physical activity), and sedentary behavior (time spent watching television and or playing computer games) were the independent factors considered in this study.

\section{Operational definitions}

The term "high school adolescents" refers to those high school students whose ages are between 10 and 19 years old in accordance with the WHO definition. While over-nutrition is when the student is classified as having overweight or obesity according to a specific cutoff point, where obesity is defined as BMI-for-age specific 95th percentile or BMI for age $Z$ score above +2 . Overweight was defined as having a BMI between the 85 th and 95 th percentiles or a $Z$ score between 1 and $2 .{ }^{23}$ Physical activity refers to activities like cleaning, painting, walking, cycling, plastering, doing household chores, and swimming, which are included as moderate physical activities; whereas activities like carrying heavy loads, running, and strenuous sports are included as vigorous physical activities. Physically active is defined as having at least 600 MET minutes per week of total physical activity, while physically inactive is defined as having less than 600 MET minutes per week. ${ }^{24}$

\section{Data collection procedures}

A structured questionnaire was conducted through a face-to-face interview with respondents or caregivers. In addition, anthropometric measurements (weight, and height measurement) were used to collect the data. The tool was developed in English and translated to local languages and pretested on 5\% of the total sample ( 25 students) from unsampled high schools. Sociodemographic information, dietary habits, physical activities, and other variables were gathered. A validated semiquantitative Food Frequency Questionnaire (FFQ) on fruit, vegetables, meat, milk and milk products, soft drinks, snacks, regular meals, and sweet food consumption was applied to capture the dietary intakes and patterns over the past one month. The tools were adapted from the WHO Steps instrument for chronic disease risk surveillance. $^{25}$

The WHO global physical activity questionnaire (GPAQ) for physical activity surveillance was used to measure the physical activity pattern among school adolescents in three major dimensions: activity at work, travel to and from places, recreational activities, and sedentary behaviour. The activity level of the study participants was ascertained in reference to the standard WHO total physical activity calculation guide, and the level of total physical activity was categorized as physically active or in-active, based on a cutoff point (600 MTE/week). ${ }^{24}$ The tool is appropriate and valid to assess the level of physical activity based on the weekly metabolic equivalent calculation. ${ }^{26}$

While anthropometric measurement of weight and height was done by calibrated equipment following standard procedures. Shoes and clothing were considered during the weight measurement under light and optimal clothing 
standardized techniques. The weight measurement was taken by a digital weight scale (SECA made in Germany, with a carrying capacity of $150 \mathrm{~kg}$ and $100 \mathrm{~g}$ precision) by making the weight of the participant evenly distributed on both feet. A portable stadiometer (SECA Germany, $0.1 \mathrm{~cm}$ precision) was used to measure height. The height was measured in the Frankfurt position with the body in touch with the measuring board and the line of sight facing parral to the ground, where the weight and height measurements were recorded to the nearest $0.1 \mathrm{~kg}$ and $0.1 \mathrm{~cm}$, respectively.

\section{Data quality assurances}

Data collectors were trained for one day on the overall data collection process and each anthropometric measurement. Specific data quality assurance measures were undertaken during the development, data collection, cleaning, entry, and analysis. A pretest was conducted on $26(5 \%)$ of the total sample, where necessary amendments and a selection of reliable anthropometric measures were taken. Close supervision, daily monitoring, and on-the-spot checkups for completed questionnaires and consistency checks were done. Anthropometric measurements of weight and height were taken in triplicate for each participant. Calibration of the weight measuring SECA was done to zero, before each measurement. The reliability of intra- and inter-observers' reliability was checked with the calculation of technical error of measurement. ${ }^{27}$

\section{Data processing, analysis and presentation}

The data was entered into Epi-Data version 3.1 and analysed in SPSS version 20. The WHO Anthro-Plus (version 1.0.4.0) was used to calculate the BMI for age $Z$ score for nutritional assessment. Normality of continuous variables was done using a Kolmogorov-Smirnov test.

Descriptive analyses with the use of tables and graphs were used to describe, summarize, and present the data. The wealth index was developed using principal component analysis of the 15 dummy coded asset variables. The developed factor scores were ranked in three categories. Assumptions for the appropriateness of factor analysis were checked using the presence of substantial correlations ( $>0.3)$, Kaiser-Mayer-Olkin for sample adequacy for the set of variables $(>0.5)$ and Bartlett's test of sphericity (0.05). All assumptions were met and four factors were computed. Then, the factor score was ranked and presented in the form of wealth quintiles.

The outcome variable was recategorized as overnourished ("failure") and otherwise ("success"). A bivariable and multivariable binary logistic regression was conducted to assess factors associated with overnutrition. Variables with a p-value below 0.25 and important variables were candidate for the multi-variable logistic regression model. Statistical significance was declared at a p-value below 0.05. All statistical tests were considered significant at a p-value less than 0.05. The model's fitness was checked using the Hosmer-Lemeshow model and omnibus tests. Crude and adjusted odds ratios (COR and AOR with 95\% confidence intervals were reported.

\section{Ethical considerations}

This study was approved by Dire Dawa University, Institutional Research Ethical Review Board. Written informed consent (for those aged above 18 years) and assent (for those aged below 18 years) was taken from each study participant and/or their immediate care givers after explaining the purpose, procedures, risks, and benefits of the study. All ethical principles and standards were respected throughout the conduct of the study. The data collected from study participants was kept strictly confidential and will not be shared with third parties.

\section{Results}

\section{Socio-demographic and economic characteristics}

In this study, a total of 498 adolescents (98.4\%) gave complete responses, with a mean age of 15.4 (1.9 SD). More than half of the respondents-269 (54.0\%) and $250(50.2 \%)$-were females and from government schools, respectively. Regarding the educational status, $54(10.8 \%)$ and $107(21.5 \%)$ of the respondents reported that their father and mother were illiterate, respectively. While more than half $(53.6 \%)$ of the mothers who participated were housewives without a formal job, a total of 23.5 and $21.5 \%$ of the adolescents' fathers were working in government organizations and private 
jobs, respectively. Concerning the socioeconomic status of the household, $71 \%$ of adolescents were from low or middle socioeconomic classes, while $29 \%$ were from high socioeconomic classes (Table 1).

\section{Dietary habits of adolescents}

Almost all (96.2\%) of the respondents had consumed cereal-based foods at least once a week. Two hundred thirty (64.7\%) consumed fruits, and $73.9 \%$ consumed vegetables three or more times per day. Almost half of the students, $(49.8 \%)$ and $202(39.6 \%)$ did not consume any dairy products or animal-source foods, respectively. While $465(91.2 \%)$ of the students had a typical three to four meals a day. Among the respondents, 45 (9\%) did not consume fruits; $347(43.9 \%)$ consumed fruits one day per week, and 296 (37.4\%) consumed fruits two or more days per week. Eighty-one (10.2\%) did

Table I Socio-demographic characteristics of $(n=498)$ adolescents in high schools from eastern Parts of Ethiopia

\begin{tabular}{|c|c|c|c|}
\hline Variables & & Frequency $(n=498)$ & Percentage \\
\hline \multirow[t]{2}{*}{ Sex } & Male & 229 & $46.0 \%$ \\
\hline & Female & 269 & $54.0 \%$ \\
\hline \multirow[t]{2}{*}{ School type } & Government & 250 & $50.2 \%$ \\
\hline & Private & 248 & $49.8 \%$ \\
\hline \multirow[t]{4}{*}{ Fathers' education } & No formal education & 54 & $10.8 \%$ \\
\hline & Primary & 42 & $8.4 \%$ \\
\hline & Secondary & 155 & $31.1 \%$ \\
\hline & College and above & 247 & $49.6 \%$ \\
\hline \multirow[t]{4}{*}{ Mothers' education } & No Formal education & 107 & $21.5 \%$ \\
\hline & Primary & 84 & $16.9 \%$ \\
\hline & Secondary & 124 & $24.9 \%$ \\
\hline & College and above & 183 & $36.7 \%$ \\
\hline \multirow[t]{5}{*}{ Fathers' occupation } & Farmer & 16 & $3.2 \%$ \\
\hline & Merchant & 135 & $27.1 \%$ \\
\hline & Government employee & 107 & $21.5 \%$ \\
\hline & Daily laborer & 125 & $25.1 \%$ \\
\hline & Private & 115 & $23.1 \%$ \\
\hline \multirow[t]{6}{*}{ Mothers' occupation } & House wife & 267 & $53.6 \%$ \\
\hline & Merchant & 64 & $12.9 \%$ \\
\hline & Government employee & 69 & $13.9 \%$ \\
\hline & Daily laborer & 36 & $7.2 \%$ \\
\hline & Private & 57 & $11.4 \%$ \\
\hline & Other & 5 & $1.0 \%$ \\
\hline \multirow[t]{3}{*}{ House hold wealth status } & Low & 250 & $50.2 \%$ \\
\hline & Middle & 102 & $20.5 \%$ \\
\hline & High & 146 & $29.3 \%$ \\
\hline
\end{tabular}


not consume vegetables, 47 (59.8\%) consumed vegetables 1-2 days per week, and 236 (29.8\%) consumed vegetables three or more days per week. The majority of 565 (71.4\%) of participants did not consume any animal product food items frequently, and the rest (28.6\%) consumed animal product food items frequently (Table 2).

Table 2 Dietary habit of $(n=498)$ adolescents high school students in eastern Parts of Ethiopia

\begin{tabular}{|c|c|c|c|}
\hline Variables & & Frequency & Percentage \\
\hline \multirow[t]{4}{*}{ Consuming fruit in a week } & None & 45 & $9 \%$ \\
\hline & $\mathrm{I}-2 \mathrm{x} / \mathrm{wk}$ & 378 & $75.9 \%$ \\
\hline & $3-4 x / w k$ & 40 & $8 \%$ \\
\hline & $5-7 x / w k$ & 35 & $7 \%$ \\
\hline \multirow[t]{4}{*}{ Consuming cereals in a week } & None & 16 & $3.2 \%$ \\
\hline & $\mathrm{I}-2 \mathrm{x} / \mathrm{wk}$ & 71 & $14.3 \%$ \\
\hline & $3-4 x / w k$ & 183 & $36.7 \%$ \\
\hline & $5-7 x / w k$ & 228 & $45.8 \%$ \\
\hline \multirow[t]{4}{*}{ Eating vegetables in week } & None & 29 & $5.8 \%$ \\
\hline & $1-2 x / w k$ & 403 & $80.9 \%$ \\
\hline & $3-4 x / w k$ & 28 & $5.6 \%$ \\
\hline & $5-7 x / w k$ & 38 & $7.6 \%$ \\
\hline \multirow{4}{*}{$\begin{array}{l}\text { Consuming milk and milk } \\
\text { products in a week }\end{array}$} & None & 217 & $43.6 \%$ \\
\hline & $\mathrm{I}-2 \mathrm{x} / \mathrm{wk}$ & 170 & $34.1 \%$ \\
\hline & $3-4 x / w k$ & 77 & $15.5 \%$ \\
\hline & $5-7 x / w k$ & 34 & $6.8 \%$ \\
\hline \multirow[t]{4}{*}{ Soft drink in week } & None & 73 & $14.6 \%$ \\
\hline & $\mathrm{I}-2 \mathrm{x} / \mathrm{wk}$ & 371 & $74.1 \%$ \\
\hline & $3-4 x / w k$ & 26 & $5.2 \%$ \\
\hline & $5-7 x / w k$ & 31 & $6.2 \%$ \\
\hline \multirow{4}{*}{$\begin{array}{l}\text { Sweet food consumption per } \\
\text { week }\end{array}$} & None & 174 & $34.9 \%$ \\
\hline & $\mathrm{I}-2 \mathrm{x} / \mathrm{wk}$ & 168 & $33.7 \%$ \\
\hline & $3-4 x / w k$ & 76 & $15.3 \%$ \\
\hline & $5-7 x / w k$ & 80 & $16.1 \%$ \\
\hline \multirow[t]{4}{*}{ Eating meat in a typical week } & None & 240 & $48.2 \%$ \\
\hline & $\mathrm{I}-2 \mathrm{x} / \mathrm{wk}$ & 211 & $42.4 \%$ \\
\hline & $3-4 x / w k$ & 15 & $3 \%$ \\
\hline & $5-7 x / w k$ & 32 & $6.4 \%$ \\
\hline \multirow[t]{2}{*}{ Snack } & Yes & 387 & $77.7 \%$ \\
\hline & No & 111 & $22.3 \%$ \\
\hline \multirow[t]{2}{*}{ Eating while watching television } & Yes & 261 & $52.4 \%$ \\
\hline & No & 237 & $47.6 \%$ \\
\hline
\end{tabular}


Almost two-thirds of adolescents ( $71 \%$ ) and $65 \%$ consume soft drinks one to two times per week and have a habit of consuming sweet foods at least once per week, respectively. A significantly higher percentage of adolescents (77.8\%) had the habit of snack consumption. More than half, 261 (52.4\%), consume snacks and other foods while watching television programs. Regarding typical meat consumption, $48 \%$ of adolescents reported that they did not consume meat and meat products, while only $6.4 \%$ of them consumed meat on a daily basis (Table 2 ).

\section{Physical activity characteristics of respondents}

A significant number of students, 409 (82.1\%), were not involved in any work activities along with their education. The majority (62.7\%) of adolescents were involved in moderate-to-vigorous sports activities, with an average sedentary stay time of $3.78( \pm 1.6 \mathrm{hrs})$. A total of 161 (32.3\%) students took a walk or used a bicycle from home to school, while $62(12.4 \%)$ took other transportation. More than three-fourths, or $80 \%$, of students reported being involved in low or moderate physical activity. In addition, $42.6 \%$ of students had a sedentary stay time of more than three hours. Interestingly, $78.5 \%$ and $63.7 \%$ of students were not involved in either vigorous or moderate-intensity physical activity, respectively (Table 3).

\section{Burden of overnutrition among adolescents}

Among adolescents, a total of 118 (23.7\%: 95\% CI: 20-27.4) and 12 (2.4\%; 9\% CI: 1.05, 3.7\%) were overweight and obese, respectively. While the combined prevalence of overnutrition (both overweight and obesity) was $26.1 \%$ (95\% CI: $22.0 \%, 30.2 \%$ ) (Figure 1).

Disaggregated by sex of the students, the magnitude of overweight and obesity among female students (17.9\% and $2 \%$, respectively) was significantly higher than among male students $(5.8 \%$ and $0.4 \%)$, respectively. Also, overweight and obesity were more prevalent among private high school adolescents (20.9\% and $1.6 \%$, respectively) than in public high schools $(2.8 \%$ and $0.8 \%$, respectively).

Table 3 Physical activity related characteristics of adolescents in eastern Parts of Ethiopia $(n=498)$

\begin{tabular}{|c|c|c|c|}
\hline Variables & & Frequency & Percentage \\
\hline \multirow{2}{*}{$\begin{array}{l}\text { Working beside } \\
\text { education }\end{array}$} & Yes & 89 & $17.9 \%$ \\
\hline & No & 409 & $82.1 \%$ \\
\hline \multirow{4}{*}{$\begin{array}{l}\text { Vigorous intensity } \\
\text { activities }\end{array}$} & None & 394 & $79.1 \%$ \\
\hline & $\mathrm{I}-2$ & 76 & $15.3 \%$ \\
\hline & $3-4$ & 14 & $2.8 \%$ \\
\hline & $5-7$ & 14 & $2.8 \%$ \\
\hline \multirow{4}{*}{$\begin{array}{l}\text { Moderate intensity } \\
\text { activities }\end{array}$} & None & 366 & $73.5 \%$ \\
\hline & $\mathrm{I}-2$ & 93 & $18.7 \%$ \\
\hline & $3-4$ & 24 & $4.8 \%$ \\
\hline & $5-7$ & 15 & $3.0 \%$ \\
\hline \multirow[t]{4}{*}{ Walking/using bicycle } & None & 62 & $12.4 \%$ \\
\hline & $\mathrm{I}-2$ & 63 & $12.7 \%$ \\
\hline & $3-4$ & 212 & $42.6 \%$ \\
\hline & $5-7$ & 161 & $32.3 \%$ \\
\hline
\end{tabular}

(Continued) 
Table 3 (Continued).

\begin{tabular}{|c|c|c|c|}
\hline Variables & & Frequency & Percentage \\
\hline \multirow{4}{*}{$\begin{array}{l}\text { Vigorous intensity sport } \\
\text { activities }\end{array}$} & None & 391 & $78.5 \%$ \\
\hline & $\mathrm{I}-2$ & 71 & $14.3 \%$ \\
\hline & $3-4$ & 21 & $4.2 \%$ \\
\hline & $5-7$ & 15 & $3.0 \%$ \\
\hline \multirow{4}{*}{$\begin{array}{l}\text { Moderate intensity sport } \\
\text { activities }\end{array}$} & None & 317 & $63.7 \%$ \\
\hline & $\mathrm{I}-2$ & 132 & $26.5 \%$ \\
\hline & $3-4$ & 26 & $5.2 \%$ \\
\hline & $5-7$ & 23 & $4.6 \%$ \\
\hline \multirow[t]{3}{*}{ Physical activities } & High & 96 & $19.2 \%$ \\
\hline & Medium & 199 & $40 \%$ \\
\hline & Low & 203 & $40.8 \%$ \\
\hline \multirow[t]{2}{*}{ Sedentary behavior } & $<3 \mathrm{hr}$ & 286 & $57.4 \%$ \\
\hline & $\geq 3 \mathrm{hr}$ & 212 & $42.6 \%$ \\
\hline
\end{tabular}

\section{Factors associated with overnutrition among adolescents}

A step-wise backward binary logistic regression analysis was done to identify factors associated with overnutrition among adolescents. The associations between socio-demographic, dietary/eating habits, physical activity, and sedentary lifestyle-related factors and overnutrition were analyzed using bivariable and multivariable binary logistic regression analysis. Under the bivariable logistic regression analysis, obesity was significantly associated with school type, sex, snacking, sedentary physical behavior, eating while watching TV, grade level, sweet food consumption, moderate or vigorous intensity sports activity, and mode of transportation from home to school, at a p-value less than 0.05 (Table 4).

Female adolescents $(\mathrm{COR}=3.72 ; 95 \% \mathrm{CI}: 2.37,5.85)$, and those from a higher wealth quintile $(\mathrm{COR}=163.4 ; 95 \% \mathrm{CI}$ : 39.1-682.3) were more likely to be overweight or obese than males and those from lower socioeconomic classes,

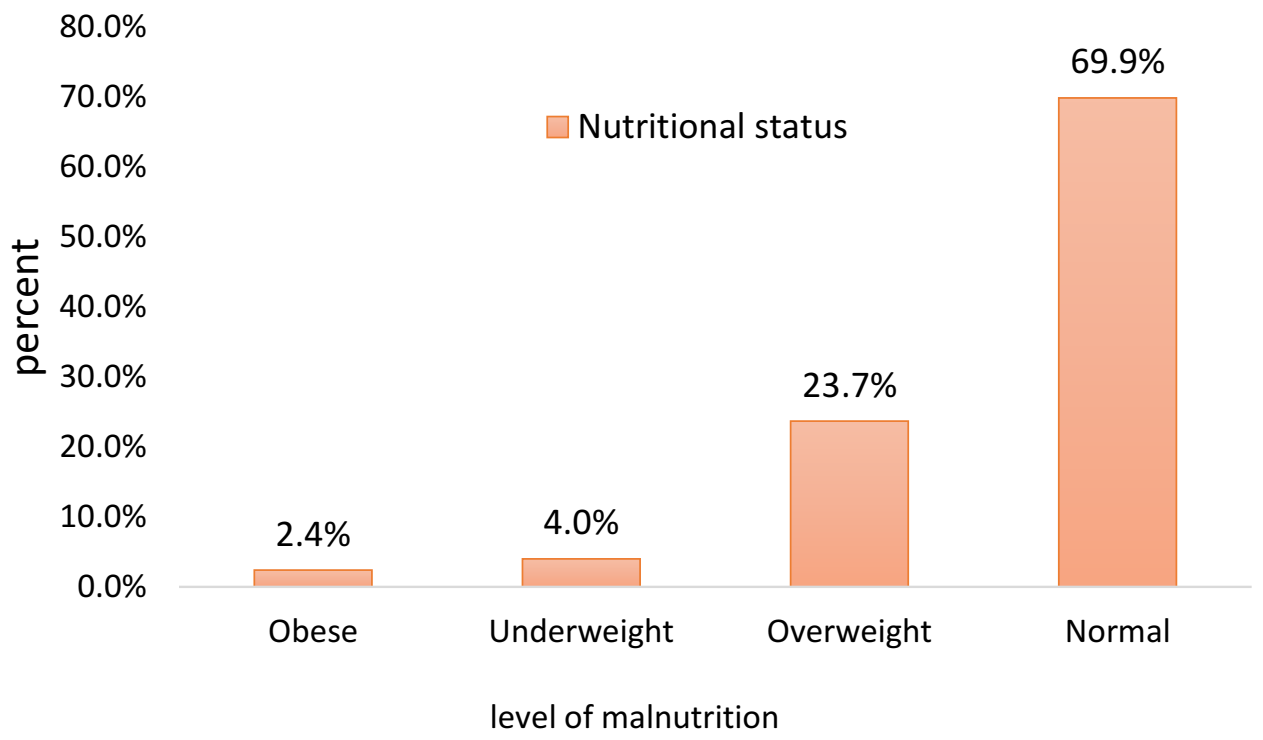

Figure I Nutritional status of high school adolescents in eastern Ethiopia $(n=498)$. 
Table 4 Bivariable logistic regression analysis of factors associated with overnutrition (verweight/obesity) among high school adolescents in Ethiopia

\begin{tabular}{|c|c|c|c|c|c|}
\hline \multirow[t]{2}{*}{ Variables } & \multirow[t]{2}{*}{ Categories } & \multicolumn{2}{|c|}{ Overnutrition } & \multirow[t]{2}{*}{ COR $(95 \% \mathrm{Cl})$} & \multirow[t]{2}{*}{ p-value } \\
\hline & & Yes (Freq (\%)) & No (Freq (\%)) & & \\
\hline \multirow[t]{2}{*}{ Sex } & Female & $99(36.8)$ & $170(63.2)$ & $3.72(2.37,5.85)$ & \multirow[t]{2}{*}{0.0001} \\
\hline & Male & $31(13.5)$ & $198(86.5)$ & reference & \\
\hline \multirow[t]{3}{*}{ Wealth index } & Low & $2(0.8)$ & $248(99.2)$ & reference & \\
\hline & Middle & $45(44)$ & $57(56)$ & $97.9(23.1-4 \mid 5.4)$ & 0.0001 \\
\hline & High & $83(56)$ & $63(44)$ & I 63.4 (39.1-682.3) & 0.0001 \\
\hline \multirow[t]{2}{*}{ Fathers' literacy } & Illiterate & 17 (3I.5) & $37(68.5)$ & $1.35(0.73-2.48)$ & \multirow[t]{2}{*}{0.374} \\
\hline & Literate & II3 (25.4) & $331(74.5)$ & reference & \\
\hline \multirow[t]{2}{*}{ Mother's' literacy } & Illiterate & $32(29.9)$ & $75(70.1)$ & $1.28(0.80-2.05)$ & \multirow[t]{2}{*}{0.313} \\
\hline & Literate & $98(25.1)$ & $293(74.9)$ & reference & \\
\hline \multirow[t]{2}{*}{ School type } & Private & $112(26.1)$ & $136(54.8)$ & $10.6(6.18-18.2)$ & \multirow[t]{2}{*}{0.0001} \\
\hline & Government & $18(7.2)$ & $232(92.8)$ & reference & \\
\hline \multirow{2}{*}{$\begin{array}{l}\text { Eating while watching television } \\
\text { or studying }\end{array}$} & Eat & $103(44.9)$ & $158(45.1)$ & $5.07(3.17,8.12)$ & \multirow[t]{2}{*}{0.0001} \\
\hline & Do not eat & $27(11.2)$ & $210(89.8)$ & reference & \\
\hline \multirow[t]{2}{*}{ Work beside school } & Yes & 14 (I5.7) & $75(84.3)$ & reference & \multirow[t]{2}{*}{0.016} \\
\hline & No & $116(28.4)$ & $293(71.6)$ & $2.12(1.15-3.90)$ & \\
\hline \multirow[t]{2}{*}{ Sweet food consumption } & Yes & $76(47.5)$ & $84(52.5)$ & $4.75(3.11-7.28)$ & \multirow[t]{2}{*}{0.0001} \\
\hline & No & $54(16)$ & $284(84)$ & reference & \\
\hline \multirow[t]{2}{*}{ Snacking } & Yes & $120(3 \mid)$ & $267(69)$ & $4.53(2.29,9.0)$ & \multirow[t]{2}{*}{0.0001} \\
\hline & No & $10(9)$ & $101(91)$ & reference & \\
\hline \multirow[t]{2}{*}{ Soft drink consumption } & $<3 x / w k$ & $120(27.1)$ & 322 (76.9) & I.7I (0.84-3.5I) & \multirow[t]{2}{*}{0.217} \\
\hline & $\geq 3 x / w k$ & $10(17.9)$ & $46(82.1)$ & reference & \\
\hline \multirow[t]{2}{*}{ Meat consumption } & Yes & $74(30.8)$ & $166(69.2)$ & $1.6 \mathrm{I}(\mathrm{I} .07-2.4 \mathrm{I})$ & \\
\hline & No & $56(21.7)$ & $202(78.3)$ & reference & \\
\hline \multirow[t]{2}{*}{ Sedentary behavior } & $\geq 3 \mathrm{hr}$ & $75(35.4)$ & $137(64.6)$ & $2.29(1.53,3.46)$ & \multirow[t]{2}{*}{0.0001} \\
\hline & $<3 \mathrm{hr}$ & $55(19.2)$ & $231(80.8)$ & reference & \\
\hline \multirow[t]{2}{*}{ Fruit consumption } & $\begin{array}{l}\text { Less than } 3 x \\
\text { per wk }\end{array}$ & $|2|(28.6)$ & 302 (7I.4) & $2.94(1.42-6.08)$ & \multirow[t]{2}{*}{0.004} \\
\hline & $\begin{array}{l}\text { At least } 3 \times \text { per } \\
\text { wk }\end{array}$ & $9(12)$ & $66(88)$ & reference & \\
\hline \multirow[t]{2}{*}{ Cereal consumption } & No & $3(18.8)$ & $13(8 \mid .2)$ & reference & 0.499 \\
\hline & Yes & $127(26.3)$ & $355(75.7)$ & $1.55(0.44-5.53)$ & \\
\hline Vegetable consumption & No & $4(13.8)$ & $25(86.2)$ & reference & 0.130 \\
\hline & Yes & $126(26.9)$ & $343(73.1)$ & $2.30(0.78-6.73)$ & \\
\hline
\end{tabular}


respectively. Students who attended private schools (COR $=10.6$; 95\% CI: 6.18-18.2) and those who ate while watching television $(\mathrm{COR}=5.07 ; 95 \% \mathrm{CI}: 3.17,8.12)$ had a ten-fold and five-fold increased risk of being overweight or obese, respectively. In addition, students from illiterate families were found to have a higher risk of being overweight or obese, but not statistically significant. Furthermore, adolescent students who are not involved in work along with their studies $(\mathrm{COR}=2.12$; 95\% CI: $1.15-3.90)$ and the habit of sweet food consumption (COR $=4.75 ; 95 \% \mathrm{CI}$ : $3.11-7.28)$ were two and five-fold higher risk of being overweight and obese, respectively (Table 4).

Having a habit of snacking $(\mathrm{COR}=4.53 ; 95 \% \mathrm{CI}: 2.29,9.0)$ is positively associated with an increased risk of overweight and obesity. When compared to adolescents who did not consume meat, meat consumption was associated with a higher burden of overnutrition ( $\mathrm{COR}=1.61 ; 95 \% \mathrm{CI}: 1.07-2.41)$. Adolescents who consumed fruit less than three times per week (COR $=2.94$; 95\% CI: $1.42-6.08)$ and vegetables less than three times per week $(\mathrm{COR}=2.30 ; 95 \%$ CI: 0.78-6.73) had a higher risk of being undernourished. In addition, students with a higher stay in sedentary life (at least three hours) (COR $=2.29 ; 95 \%$ CI: 1.53, 3.46) were 2.3 times more likely to be overweight or obese as compared to those with a lower stay in sedentary life (COR $=1.97 ; 95 \%$ CI: $1.53,3.46$ ) were also 2.3 times more likely to be overweight or obese as compared to those with a lower (Table 4).

While in the multivariable logistic regression analysis, six explanatory variables (school type, sex of students, snacking habit, sedentary lifestyle, eating while watching television, and sweet food consumption of more than 3 days per week) were significantly and independently associated with overweight or obesity. The model fitness was checked using a Hosmer-Lemeshow goodness of fit ( $\mathrm{P}$-value $=0.32$ ), which showed a fitted model.

Female students (AOR $=3.32$; 95\% CI: 1.65-6.63), and students from private high schools (AOR $=4.97$; 95\% CI: 1.72 14.35) were three and five times more likely to be over nourished than males and from government high schools. In addition, students with the habit of eating snacks ( $\mathrm{AOR}=3.05 ; 95 \% \mathrm{CI}$ : 1.11-8.36) and eating while watching television and studying $(\mathrm{AOR}=4.63 ; 95 \% \mathrm{CI}: 1.96-10.95)$ had a three and 4.5-fold increased burden of overnutrition as compared to their counter parts. While adolescents with a habit of sweet food consumption ( $\mathrm{AOR}=6.26$; $95 \% \mathrm{CI}: 3.14-12.5$ ) and extended sedentary lifestyles above three hours per day ( $\mathrm{AOR}=3.20 ; 95 \% \mathrm{CI}$ : 1.67-6.10) were significantly positively associated with increased risk of being over nourished (Table 5).

Table 5 Multivariable binary logistic model Showing factors associated with overnutrition among high school adolescents in Ethiopia

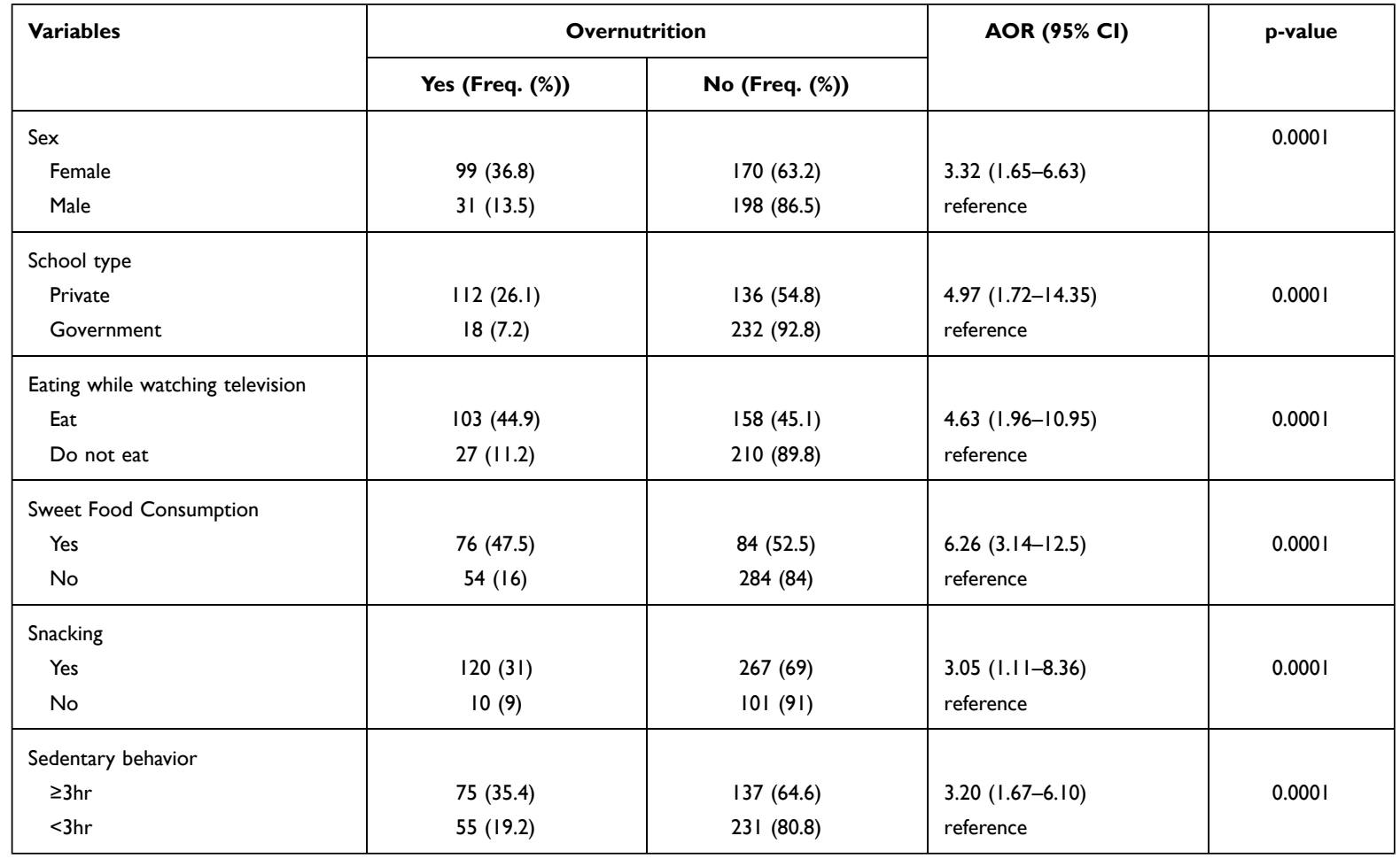




\section{Discussion}

This study was to explore the magnitude and factors associated with overweight and obesity among high school adolescents in Ethiopia. We found that $23.7 \%$ and $2.4 \%$ of adolescents were overweight and obese, respectively, while $26.1 \%$ had overnutrition. The overall prevalence of overweight and obesity in this study is higher than the prevalence reported by studies conducted in Addis Ababa, ${ }^{17}$ Bahir Dar, ${ }^{14}$ Gondar, ${ }^{16}$ and Hawassa (12.7 and 2.7\%). ${ }^{15}$ In addition, a prevalence of $3.5 \%$ (Eriterea) to $63 \%$ (Seychelles), where a higher burden of obesity was reported from North African countries. ${ }^{28}$ A pooled estimate also showed that $8.9 \%$ and $2.4 \%$ were overweight or obese. ${ }^{20}$ The variation in the study results might have occurred because of the differences in dietary intakes, physical activity levels, and sedentary behaviors among adolescents in the study areas. In addition, the more urbanized and hotter weather conditions usually limit physical activity and take transport instead of walks. In addition, the availability of industrially processed foods, sweet local foods, and diverse dietary behaviors predispose them to a higher prevalence of overnutrition. This huge burden of overnutrition makes the study area one of the hotspot areas, and targeted obesity and overweight prevention and control are mandatory to be implemented.

In the present study, the prevalence of overweight/obesity among female adolescents was 3 times higher than among male adolescents. A pooled analysis also revealed that female students were three times more likely than male students to be overweight or obese $(\mathrm{AOR}=3.23 ; 2.03,5.13)$. A Study conducted in seven African countries, Gonder, ${ }^{29}$ and Addis $\mathrm{Ababa}^{17}$ found a significant association between sex and overweight/obesity, with females being more likely than males to be overweight or obese. The possible reason could be that boys are generally more physically active compared to girls, especially during adolescence. ${ }^{30}$ Also, concerns about body image, by adolescent girls, may lead to problematic eating behaviors such as irregular meal patterns that may result in increased weight gain. ${ }^{31}$ This influence of gender on obesity can be attributed to hormonal changes at puberty resulting in fat accumulation and families' negative attitudes toward student participation in outdoor activities due to certain cultural and religious restrictions. However, this finding was inconsistent with a study done in Bahir Dar City, Northwest, Ethiopia, ${ }^{14}$ where the prevalence was more among boys than girls, which might be due to the sampling or actual real differences.

In this study, the overall prevalence of overweight and obesity was five times higher in adolescents studying in private high schools than in governmental high schools. In addition, students from higher socioeconomic classes were more likely to be overnourished. Similar findings were observed from different countries, including Pakistan, ${ }^{32}$ Nigeria, ${ }^{33}$ Kenya, ${ }^{34}$ and a study done in Gonder ${ }^{16}$ high school adolescents. This might be due to the fact that students attending private schools are more likely to be from high socioeconomic classes, where dietary consumption, dietary habits, and exercise patterns are different and unhealthy from those attending public schools. The study also found that students from affluent families were three times more likely to be overweight or obese (AOR $=3.16 ; 95 \%$ CI: 1.87, 5.34). ${ }^{20}$ Students from families with higher socioeconomic status are more likely to be exposed to highly processed, energy-dense foods, sweet foods, more luxurious lives, and a motorized way of life compared to those from government schools. Above all, the state of nutritional transition is worse in recently urbanized developing countries, where availability and preference for such foods is high. ${ }^{35}$

In addition to this, respondents who onsumed sweet food (Mushebek, Beklawa, chocolate, biscuits, pizza, and burgers) more than three times a week were six times more likely to be overweight or obese. This finding is comparable to the study done in the Arada sub-city of Addis Ababa and among adolescents in Gondar town, North West Ethiopia. ${ }^{16}$ Similarly, those who prefer sweet foods have a higher risk of obesity or being overweight (AOR $=2.78 ;$; $95 \%$ CI: $1.97-$ $3.93) .{ }^{20} \mathrm{It}$ is because of the excess calories and their ability to cause hunger immediately after consumption and trigger excessive food consumption that they are predisposed to overnutrition. ${ }^{28,36}$ In the current globalized world, where access to processed foods, along with adolescents' preference for such foods, and the increased price of nutritious, healthy, and organic foods, ${ }^{37}$ greatly contribute to the change in the dietary patterns of individuals. ${ }^{38}$

The odds of being overweight or obese among adolescents who eat while watching TV and studying were four times higher than their counterparts. In different parts of the world, there was a positive, significant association between eating while watching TV and studying and time spent watching television or using a computer and being overweight. ${ }^{39,40}$ This finding was consistent with previous research from Bangladesh and the United States. ${ }^{41,42}$ The odds of being overweight or obese among adolescents with higher hours of sedentary behaviors were three times more likely than those who do not 
consume sweet food or less frequently. ${ }^{20}$ This is supported by the fact that physical inactivity predisposes adolescents 3.4 times more often to obesity or being overweight. The result was consistent with studies conducted in Ethiopia, ${ }^{16}$ and Pakistan. ${ }^{31}$ Adolescents are also predisposed to different forms of disordered eating behavior, which greatly affect and disturb the normal physiology ${ }^{43}$.

This could be explained as sedentary behavior and excessive binge eating while on social media, television, or others, usually increases the gap between energy intake and expenditure. ${ }^{44}$ Furthermore, those with a longer stay in sedentary life usually limit physical activities ${ }^{45}$ and non exercise activities, which are the most important means of losing energy expenditure and maintaining optimal adiposity. ${ }^{15,40,41}$ Similarly, a study in Morocco found that adolescents who watched TV more than 4 hours a day, were more prone to obesity than those who watched less than 4 hours a day. ${ }^{30}$ This increased risk and higher burden of overnutrition can be partially explained by the lack of regular activities resulting in low energy expenditure. ${ }^{24}$

In a country where noncommunicable diseases account for more than $70 \%$ of hospital deaths and where the problem is deeply rooted in abnormal nutrition and body weight (obesity), it is critical strategic direction to target overnutrition as a public health problem. Furthermore, the existence of a triple burden of malnutrition and close links between childhood undernutrition and adulthood chronic noncommunicable diseases, ${ }^{28,38,44}$ necessitates a multifaceted public health strategy aimed at adolescents, where the problem is reported to be prevalent. ${ }^{28}$

The findings of this study should be thought about in the light of some limitations of this study. All variables that could affect nutritional status, such as family history, genetic factors, parental BMI, medication use, and assessment of feeding practices during early childhood, were not possible to assess. This study did not use the waist to hip circumference ratio, which could identify the risk of central obesity as the BMI for age. In addition, it would be better if quantitative dietary consumption data were captured to actually measure the actual dietary intake rather than the usual FFQ.

\section{Conclusion and Recommendations}

Overnutrition among high school adolescents is a major public health problem. Students attending school privately, females, with the habit of snacking, sweet food consumption, sedentary lifestyles, and eating while studying or watching television were significant predictors of overnutrition among school adolescents. Public health interventions should consider that overnutrition among adolescents is a major public health issue and be incorporated into the main health agenda to be addressed in the area. School-based nutrition education should be encouraged and supported, targeting healthy eating patterns. In addition, schools should encourage planned physical activity programs and sports games that initiate students' regular physical activity for obesity prevention and control. Obesity and overweight prevention and control should give special emphasis to private school students and those from higher socioeconomic classes. Students and families should be aware of the harm of being overweight and obesity, and should encourage their children to have regular physical activity, take part in non-exercise activities (work), and have a healthy dietary consumption, specifically minimizing sweet, sugary, and refined foods.

\section{Abbreviations}

A/COR, adjusted or crude odds ratio; BMI, body mass index; CI, confidence interval; FFQ, Food Frequency Questionnaire; GPAQ, General Physical Activity Questionnaire; UN, United Nations; WHO, World Health Organization.

\section{Data Sharing Statement}

All relevant data are within the paper.

\section{Ethical Statement}

This study was ethically approved by the Institutional Research Ethical Review committee of Dire Dawa University. Written informed consent (for those aged above 18 years) and assent (for those aged below 18 years) was taken from each study participant and/or their immediate care givers. All relevant ethical principles under the Helsinki declaration were followed and respected. 


\section{Acknowledgment}

We are grateful to all the Dire Dawa administration education bureau, each high school teacher, respondents (students), data collectors, and others for their unreserved cooperation and support for the successful completion of this study.

\section{Author Contributions}

All authors made a significant contribution to the work reported, whether that is in the conception, study design, execution, acquisition of data, analysis and interpretation, or in all these areas; took part in drafting, revising or critically reviewing the article; gave final approval of the version to be published; have agreed on the journal to which the article has been submitted; and agree to be accountable for all aspects of the work.

\section{Disclosure}

The authors declare that no conflict of interest exists.

\section{References}

1. UNFPA. Adolescent sexual and reproductive health toolkit for humanitarian setting: a companion to the inter-agency field manual on reproductive health in humanitarian settings; 2009.

2. United Nations. World population prospects-population division; 2018.

3. De Goede IH, Branje SJ, Meeus WH. Developmental changes in adolescents' perceptions of relationships with their parents. $J$ Youth Adolesc. 2009;38(1):75-88. doi:10.1007/s10964-008-9286-7

4. Nishida C, Borghi E, Branca F, de Onis M. Global trends in overweight and obesity. Energy Balance Obesity. 2017;45:604.

5. World Health organization (WHO). Obesity and Overweight. Geneva, Switherland: World Health organization; 2020:15-30.

6. Stevens GA, Singh GM, Lu Y, et al. National, regional, and global trends in adult overweight and obesity prevalences. Popul Health Metr. 2012;10 (1):1-16. doi:10.1186/1478-7954-10-22

7. Pigeot I, Baranowski T, Lytle L, Ahrens W. Prevention of overweight and obesity in children and adolescents: critical appraisal of the evidence base. Bundesgesundheitsblatt Gesundheitsforschung Gesundheitsschutz. 2016;59(11):1423-1431. doi:10.1007/s00103-016-2449-x

8. UNICEF. UNICEF advocacy strategy guidance for the prevention of overweight and obesity in children and adolescents. New York; 2020.

9. Barker DJ, Thornburg KL. Placental programming of chronic diseases, cancer and lifespan: a review. Placenta. 2013;34(10):841-845. doi:10.1016/ j.placenta.2013.07.063

10. Barker M, Dombrowski SU, Colbourn T, et al. Intervention strategies to improve nutrition and health behaviours before conception. Lancet. 2018;391(10132):1853-1864. doi:10.1016/S0140-6736(18)30313-1

11. Smith CJ, Ryckman KK, Barnabei VM, et al. The impact of birth weight on cardiovascular disease risk in the Women's Health Initiative. Nutr Metab Cardiovasc Dis. 2016;26(3):239-245. doi:10.1016/j.numecd.2015.10.015

12. Barker DJ. The fetal and infant origins of adult disease. Br Med J. 1990;301(6761):1111. doi:10.1136/bmj.301.6761.1111

13. Abarca-Gómez L, Abdeen ZA, Hamid ZA, et al. Worldwide trends in body-mass index, underweight, overweight, and obesity from 1975 to 2016 : a pooled analysis of 2416 population-based measurement studies in 128. 9 million children, adolescents, and adults. Lancet. 2017;390 (10113):2627-2642.

14. Worku M, Gizaw Z, Kassahun Belew A, Wagnew A, Hunegnaw MT. Prevalence and associated factors of overweight and obesity among high school adolescents in Bahir Dar City, Northwest, Ethiopia: a Cross-Sectional Study. J Obes. 2021;2021:1-8. doi:10.1155/2021/8846723

15. Teshome T, Singh P, Moges D. Prevalence and associated factors of overweight and obesity among high school adolescents in urban communities of Hawassa, Southern Ethiopia. Curr Res Nutr Food Sci. 2013;1(1):23-36. doi:10.12944/CRNFSJ.1.1.03

16. Gebregergs G, Yesuf M, Beyen T. Overweight and obesity, and associated factors among high school students in Gondar town, north west Ethiopia. J Obes Wt Loss Ther. 2013;3(2):1-5.

17. Dereje D, Yirgu R, Chichiabellu T. Magnitude of overweight/obesity and associated factors among high school adolescents' in Addis Ababa, Ethiopia. J Nutr Disord Ther. 2018;8(2):2161-2509.

18. Misganaw A, Haregu TN, Deribe K, et al. National mortality burden due to communicable, non-communicable, and other diseases in Ethiopia, 1990-2015: findings from the Global Burden of Disease Study 2015. Popul Health Metr. 2017;15(1):1-17. doi:10.1186/s12963-016-0118-9

19. Melaku YA, Temesgen AM, Deribew A, et al. The impact of dietary risk factors on the burden of non-communicable diseases in Ethiopia: findings from the Global Burden of Disease study 2013. Int J Behav Nutr Phys Act. 2016;13(1):1-13. doi:10.1186/s12966-016-0447-x

20. Gebrie A, Alebel A, Zegeye A, Tesfaye B, Ferede A. Prevalence and associated factors of overweight/obesity among children and adolescents in Ethiopia: a systematic review and meta-analysis. BMC Obes. 2018;5(1):1-12. doi:10.1186/s40608-018-0198-0

21. Kumanyika SK. A framework for increasing equity impact in obesity prevention. Am J Public Health. 2019;109(10):1350-1357. doi:10.2105/ AJPH.2019.305221

22. Dereje D, Yirgu R, Chichiabellu T. Magnitude of overweight/obesity and associated factors among high school adolescents' in Addis Ababa Ethiopia. J Nutr Disord Ther. 2018;8(2):2161-0509.

23. World Health Organization. WHO growth reference for school aged children and adolescents; 2007.

24. World Health Organization. Global physical activity questionnaire (GPAQ) analysis guide. Geneva; 2011.

25. World Health Organization. The WHO Stepwise approach to chronic disease risk factor surveillance (STEPS). Switzerland; 2007.

26. Cleland CL, Hunter RF, Kee F, et al. Validity of the global physical activity questionnaire (GPAQ) in assessing levels and change in moderate-vigorous physical activity and sedentary behaviour. BMC Public Health. 2014;14(1):1-11. 
27. Stomfai S, Ahrens W, Bammann K, et al. Intra-and inter-observer reliability in anthropometric measurements in children. Int J Obes. 2011;35(1): S45-S51. doi:10.1038/ijo.2011.34

28. Agyemang C, Boatemaa S, Frempong GA, Aikins A. Obesity in sub-saharan Africa. Metab Syndr. 2016;4:1-13.

29. Gebregergs GB, Yesuf ME, Beyen TK. Overweight and obesity, and associated factors among high school students in Gondar Town, North West Ethiopia. J Obes Wt Loss Ther. 2013;3(65):1-5.

30. Kabbaoui ME, Amal Bousfiha AC, Aarab L. Rachid Bencheikh and Abdelali Tazi, prevalence of and risk factors for overweight and obesity among adolescents in Morocco. East Mediterr Health J. 2018;24(6):512-521. doi:10.26719/2018.24.6.512

31. Muhihi AJ, Mpembeni RN, Njelekela MA, et al. Prevalence and determinants of obesity among primary school children in Dar Es Salaam, Tanzania. Arch Public Health. 2013;71(1):1-8. doi:10.1186/0778-7367-71-26

32. Muhammad UmairMushtaql SG, Komal Mushtaq SG. Dietary, physical activities and sedentary lifestyle associated with overweight and obesity among Pakistani primary school children. IJ Beh Nut Phy Acti. 2011;8(130):5-20.

33. Manyanga T, El-Sayed H, Doku DT, Randall JR. The prevalence of underweight, overweight, obesity and associated risk factors among school-going adolescents in seven African countries. BMC Public Health. 2014;14(1):1-11. doi:10.1186/1471-2458-14-887

34. Kyallo F, Makokha A, Mwangi AM. Overweight and obesity among public and private primary school children in Nairobi, Kenya. Health. 2013;5 (2):1-2.

35. Cusick SE, Kuch AE. Determinants of undernutrition and overnutrition among adolescents in developing countries. Adolesc Med State Art Rev. 2012;23(3):440.

36. Scott A, Ejikeme CS, Clottey EN, Thomas JG. Obesity in sub-Saharan Africa: development of an ecological theoretical framework. Health Promot Int. 2013;28(1):4-16. doi:10.1093/heapro/das038

37. Ameye H, Bachewe FN, Minten B. The rising price of nutritious foods: the case of Ethiopia. Glob Food Sec. 2021;31:100582. doi:10.1016/j. gfs.2021.100582

38. Popkin BM, Adair LS, Ng SW. Global nutrition transition and the pandemic of obesity in developing countries. Nutr Rev. 2012;70(1):3-21. doi:10.1111/j.1753-4887.2011.00456.x

39. Winkvist A, Hultén B, Kim J-L, et al. Dietary intake, leisure time activities and obesity among adolescents in Western Sweden: a cross-sectional study. Nutr J. 2015;15(1):1-12. doi:10.1186/s12937-016-0160-2

40. Liou YM, Liou TH, Chang LC. Obesity among adolescents: sedentary leisure time and sleeping as determinants. J Adv Nurs. 2010;66 (6):1246-1256. doi:10.1111/j.1365-2648.2010.05293.x

41. Zoeller Jr RF. Physical activity, sedentary behavior, and overweight/obesity in youth America: evidence from cross-sectional, longitudinal, and interventional studies. Am J Lifestyle Med. 2011;3:110-114.

42. Zoeller RF Jr. Physical activity, sedentary behavior, and overweight/obesity in youth: evidence from cross-sectional, longitudinal, and interventional studies. Am J Lifestyle Med. 2009;3(2):110-114. doi:10.1177/1559827608328735

43. Haines J, Kleinman KP, Rifas-Shiman SL, Field AE, Austin SB. Examination of shared risk and protective factors for overweight and disordered eating among adolescents. Arch Pediatr Adolesc Med. 2010;164(4):336-343. doi:10.1001/archpediatrics.2010.19

44. Hill JO, Wyatt HR, Peters JC. Energy balance and obesity. Circulation. 2012;126(1):126-132. doi:10.1161/CIRCULATIONAHA.111.087213

45. Kurdaningsih SV, Sudargo T, Lusmilasari L. Physical activity and sedentary lifestyle towards teenagers' overweight/obesity status. Int J Community Med Public Health. 2016;3(3):630-635. doi:10.18203/2394-6040.ijcmph20160623

Adolescent Health, Medicine and Therapeutics

\section{Publish your work in this journal}

Adolescent Health, Medicine and Therapeutics is an international, peer-reviewed, open access journal focusing on health, pathology, and treatment issues specific to the adolescent age group. All aspects of health maintenance, preventative measures and disease treatment interventions are addressed within the journal and practitioners from all disciplines are invited to submit their work as well as healthcare researchers and patient support groups. The manuscript management system is completely online and includes a very quick and fair peer-review system. Visit http://www.dovepress.com/testimonials.php to read real quotes from published authors.

Submit your manuscript here: http://www.dovepress.com/adolescent-health-medicine-and-therapeutics-journal 